\title{
Transfusion-Transmitted Bacterial, Viral and Protozoal Infections
}

\author{
Pankaj Abrol ${ }^{1}$ and Harbans Lal ${ }^{2}$ \\ ${ }^{1}$ Post Graduate Institute of Medical Sciences, \\ University of Health Sciences, Rohtak (Haryana) \\ ${ }^{2}$ Maharaja Agrasen Medical College, Agroha, Hissar (Haryana)
}

India

\section{Introduction}

Blood transmitted infection is the commonest cause of death after blood transfusion. All patients on regular packed cell volume (PCV) or any blood component are at increased risk of transfusion transmitted infections. The etiological agents can be virus, bacteria or protozoa. These organisms can cause clinical sickness in recipient, can persist in him as carrier state or can cause asymptomatic infection in him. Every blood bank follows screening procedures to prevent such infections but the infective agents escape detection due to window period - a period where in the infective agent's presence cannot be detected, though it is present in donor's blood. Blood banks in developed countries are doing Nucleic Acid Amplification Testing (NAT) since 1999 to screen donated blood. The window period for testing for HIV, Hepatitis B and Hepatitis C has been significantly reduced with NAT. NAT can detect low levels of viral genetic material in blood.

Patients having thalassemia major or any other chronic hemolytic anemia are on regular PCV infusion essential for their survival. Patients having hemophilia; on cryoprecipitate, fresh frozen plasma or on plasma based factors are also at increased risk. Hemophilia patients on recombinant factors VIII or IX, from the start of therapy are safe.

\section{Nuclear acid amplification testing (NAT)}

Despite improvement in $\mathrm{HIV}, \mathrm{HCV}$ and $\mathrm{HBV}$ serological tests, we still have viral transmission of these diseases because of donations that take place while donor is:

1. In pre-seroconversion window period

2. Infected with immunovariant viruses

3. A non-sero-converting chronic carrier

In most countries, the safety of blood is ensured by donor selection, testing of donations for viral markers and in the case of blood products, the inclusion of viral inactivation steps during the manufacture of the blood products. However, transmission of HIV, HBV and $\mathrm{HCV}$, continues to be a threat to safe blood transfusion, especially in developing countries. It 
is due to low numbers of voluntary donations, use of low sensitivity tests for viral screening and the high prevalence of these viruses. This has contributed to the high rate of transfusion transmitted infections compared with developed countries. In developing countries, where the majority of donors are still replacement donors, the risk of transfusion transmitted viral infections is much higher than in countries with a $100 \%$ voluntary donor base. The prevalence of post transfusion HBV and HCV in India is between 1 to 5\% [Singh, 1999]. The prevalence of HIV varies from region to region in a country.

The implementation of nucleic acid testing (NAT) over the last decade into the blood screening process has added an extra layer of safety against transmission of transfused viral infections. NAT was first introduced by the European plasma industry in 1995 and consequently for whole blood donation screening in some parts of Europe and then Asia. HCV NAT was first introduced between 1999 and 2001 in blood banks across France, Germany, Italy, Spain, Switzerland and the United Kingdom presumably as it was already mandatory for plasma screening in these countries [Pathak \& Chandrashekhar, 2010].

Serological screening of blood donor have greatly reduced, but not eliminated the risk of transmission of viral infections by transfusion of blood and blood products. Production of antibodies takes several weeks after the infection. During this serological window period, infective antigen is present in blood of the patient, but there are no detectable antibodies. The primary benefit of NAT is the ability to reduce residual risk of infectious window period (WP) donations [Wiedemann et al., 2007].

NAT screening reduces window period as follows:

1. HIV - 11 Days

2. HBV - 20 Days

3. HCV - 15 Days

The introduction of Nucleic Acid Technology testing has reduced the risk of transfusion transmitted HCV and HIV infections to approximately 1 in 1 million and 1 in 3 million respectively in Western Europe and the USA. NAT testing can detect even low level of viral genetic material.

\section{Etiology of blood transmitted infections}

1. Viruses - HIV 1 \& 2 virus, Hepatitis C, Hepatitis B, Other Hepatitis Viruses, Cytomegalovirus, Human T-Cell Leukemia Virus, Cytomegalovirus, Parvovirus, Epstein Barr virus, Human herpes virus, West Nile virus.

2. Bacterial contamination - Staphylococcus, streptococcus, Yersinia, Serratia, Acinetobacter, Pseudomonas, Escherichia etc.

3. Protozoa - Malaria, Chagas, Toxoplasmosis, Leishmaniasis, Babesiosis

4. Nematodes - Microfilariasis

\section{Transfusion transmited viral infections}

In last 2 decades, much attention has been given to prevention of viral infections like HIV-1 and 2, human T-cell lymphotropic virus (HTLV) I and II, hepatitis C virus, hepatitis B virus 
(HBV) and west Nile virus (WNV). Because of potential transmission of virus during 'immunological window period', NAT is being performed. However, it has some limitations in blood components with very low levels of viremia, which can even escape detection by NAT. Despite this limitation, the combination of both serological testing and NAT has considerably reduced the risk of viral transmission by blood transfusion.

\subsection{HIV}

Human immune deficiency virus (HIV) is an important global public health problem. HIV infection causes a broad spectrum disease and has a varied clinical course, from mild, flulike symptoms to AIDS; which is life threatening and the end stage of HIV infection. HIV is transmitted through sexual contact, sharing of HIV contaminated needles and/or syringes, transfusion of blood components, and nosocomial exposure to HIV contaminated blood or bodily fluids, and can be passed vertically from a mother to her infant.

Factors that can contribute to HIV transmission through blood transfusion include the window period (i.e. a short viraemic period in which the donor is infected with HIV at a very early stage and often tested negative in a donor screening test), HIV-antibody negative chronic carriers and HIV mutant infection. The primary source of transfusion transmitted HIV infection, however, is donations collected during the window period. Donated blood is tested for antibodies to HIV-1, HIV-1 p24 antigen test and HIV RNA test using NAT. Window period has been reduced from 42 days by HIV antibody assays in the 1980s to 16 days by HIV-1 p24 antigen test and 11 days by HIV NAT [Canadian Blood Services, 2001; Public Health Agency of Canada, 2003]. The risk of HIV transmission through blood transfusion was estimated to be 1 in 752,000 donations between 1987 and 1996. This risk has been estimated to be 1 in 1.3 million donations following the implementation of HIV-1 p24 testing, and 1 in 1.6 million donations following the implementation of HIV NAT on a pool of 24 samples.

\subsection{HCV}

Hepatitis C virus currently affects over four million people in USA. There it is the commonest transfusion transmitted infection and main indication for liver transplantation. High risk group is constituted by those who received transfusion prior to 1991 or the ones who were IV drug abusers using shared needles. Incubation period can be as long as decades and this contributes to high rate of infection. Route of infection is by and large intravenous/injection pricks. Sexual transmission is also possible. Other routes are nosocomial exposure to contaminated blood and body fluids and mother to child transmission. Hepatitis C virus subtype varies worldwide. Approximately $90 \%$ of individuals infected with $\mathrm{HCV}$ are either asymptomatic or have only mild symptoms. However, about $80 \%$ of acute infections progress to chronic infection, and almost half of those chronically infected individuals eventually develop cirrhosis or hepatocellular carcinoma after a few decades [Public Health Agency of Canada 2003].

In Europe, predominant genotypes are 1, 2 and 3. Types 1a and 3a are seen in north-western countries, whereas $1 \mathrm{~b}$ is in Hungary, Germany, Russia and Turkey. Types $1 \mathrm{a}$ and $1 \mathrm{~b}$ are common in North America. Types 1b, 2a and 2b predominate in Japan [Blood Book, 2011]. After infection, antibodies against Hepatitis C virus take 54-192 days to appear. The window 
period yielded with HCV nucleic acid amplification testing (HCV NAT) is shorter than that from the HCV antibody test. There is high risk of transfusion transmitted infection in this window. In United States there is 1 in 121,000 risk of HCV infection.

\subsection{HBV}

Hepatitis B surface antigen testing was introduced in 1970's and its transmission was consistently reduced since then. Still 300 million individuals are infected worldwide. HBV surface antigen is routinely included in donor screening but it fails to detect presence of HBV during window period. Chronic carriers of HBV may have low level viremia and may not have detectable HBsAg level, so some centres have started testing antibodies against $\mathrm{HBV}$ core protein (anti $\mathrm{HBc}$ ). Today, the residual risk of transfusion transmitted HBV infection varies between 0.75 per million blood donations in Australia, $3.6-8.5$ in the USA and Canada, 0.91 - 8.7 in Northern Europe, 7.5 - 13.9 in Southern Europe up to 200 per million donations in Hong Kong, largely reflecting the global epidemiology of HBV. Some countries with low level prevalence of HBV have implemented HBV NAT testing in plasma pools. The kinetics of viral antigen and antibody appearance during HBV infection create two different window periods in which one or the other test may fail: the "early acute phase", when serological markers are still negative and the "late chronic phase" when HBsAg may become gradually undetectable, although infectivity remains. NAT can potentially identify and can be of particular benefit in detecting HBV DNA in latent HBV infection in early acute phase/occult HBV infection, when HBV DNA is present in plasma and presence of anti-HBC and HBsAg is variable [Biswas et al., 2003].

\subsection{Hepatitis A virus}

Hepatitis A is an important vaccine preventable infectious disease. The most common mode of transmission is feco-oral. It occurs through personal contact or ingestion of contaminated food/water.

Transmission of HAV through blood transmission is not yet established. However, transmission of HAV has been reported through infusion of blood products in hemophilia patients. Since pooled plasma from multiple donors is used for preparing blood products, and the solvent-detergent method for viral inactivation is ineffective against HAV, the risk of transmission of HAV through the use of blood products, though extremely small, may still exist. Currently, blood units are not routinely tested for antibodies to HAV. It has been suggested that recipients of clotting factors receive vaccine against HAV to prevent Transfusion Transmitted hepatitis A [Moor et al., 1999].

\subsection{Hepatitis E virus (HEV)}

It's an acute infection caused by hepatitis E virus and is endemic in Asia and Africa. Mode of transmission as well as clinical presentation is same as in hepatitis A. Like hepatitis A, there are no carriers in hepatitis E. Periods of viremia are also short.

Although transmission of HEV through blood transfusion has not been established, possibility of its transmission through transfusion cannot be excluded in endemic areas. 


\section{Other hepatitis viruses}

Other transfusion transmitted viruses - TTV, SEN-V and GBV-C do not cause hepatitis or other diseased states. Routine screening before blood transfusion is not recommended [Dzieczkowski \& Anderson, 2008].

\subsection{Human T Lymphotropic virus (HTLV)}

HTLV 1 is associated with adult $\mathrm{T}$ cell leukemia/lymphoma and severe tropical spastic paraparesis. HTLV 2 is associated with milder forms of myelopathy / spastic paraparesis and pulmonary disorders. Both retroviruses have also been attributed a role in risk for developing severe asthma, respiratory and urinary tract infections, uveitis and dermatitis [Murphy et al., 1994, 2004]. Enzyme immunosorbent assays and particle agglutination tests are used for screening, followed by confirmatory tests of positive tests. No vaccine is available for prophylaxis and no effective antiviral drug is available for treatment.

\subsection{Cytomegalovirus (CMV)}

This omnipresent virus infects more than half of general population. Prevalence of CMV antibodies increases with age. Acute infection is usually asymptomatic. This is transmitted by infected WBC's found in packed red cells or platelet components. Leukoreduction reduces the risk of CMV transmission, regardless of serological status of donor. Immunocompromised patients, CMV seronegative transplant recipients, pregnant women and neonates form the high risk group. Pre-storage leukodepletion of blood components may be as effective as the use of CMV seronegative blood components [Vamvakas, 2005; Blajachman et al., 2001; Blajachman, 2006]. Donor blood is not routinely tested for CMV.

\subsection{Parvovirus B-19}

Blood components as well as pooled plasma products can transmit parvovirus B-19. Patients having thalassemia or hemophilia are at risk. Infection can also be transmitted through respiratory secretions as well vertically from mother to child. This is etiological agent of erythema infectiosum, or $5^{\text {th }}$ disease in children. Patient may remain asymptomatic or present with mild symptoms like fever. Parvovirus B-19 has affinity for erythroid precursors and in some patients, inhibits both production and maturation of erythrocytes [Dzieczkowski \& Anderson, 2008]. Patient can develop pure red cell aplasia or develop acute aplastic crisis in patients having hemolytic anemia like sickle cell disease or thalassemia. Infection of a seronegative pregnant mother may result in fetal anemia and/or fetal death.

The prevalence of antibodies to HPV-B19 among blood donors seems to be very low. Currently, blood units are not routinely screened for serologic markers of HPV-B19 infection, and the viral inactivation methods are ineffective against HPV-B19 [Koenigbauer et al., 2000]. Therefore, a very low risk of HPV-B19 transmission through blood transfusion, in particular through the infusion of blood products, may exist. It has also been suggested that high-risk individuals receive anti-HPV-B19 negative blood components in order to 
prevent/reduce severe complications associated with HPV-B19 infection [Wu et al., 2005; Plentz et al., 2005].

\subsection{Epstein-Barr virus (EBV)}

Epstein-Barr virus is common in general population. In children, infection is usually asymptomatic, whereas in adults, it often results in mild symptoms like fever and sore throat. EBV is generally associated with Burkitt's lymphoma, nasopharyngeal carcinoma and B-cell lymphoma in immune-compromised patients.

It is transmitted primarily through person to person contact via saliva. It is also transmitted through blood transfusion. Since antibodies to EBV are present in up to $90 \%$ of population, it would be impractical to eliminate sero-positive donors by serological screening tests. Leukodepletion remains best option to reduce EBV transmission through blood transfusion [Public Health Agency of Canada, 2003; Sher, 1999].

\subsection{Human herpes virus 6 (HHV-6)}

HHV-6 is causative agent of $6^{\text {th }}$ disease. It presents in children as persistent fever. It is generally asymptomatic in adults. Significant symptoms appear in immunocompromised individuals. HHV-6 causes persistent infection and there is high prevalence of antibodies among blood donors. Currently donor blood is not routinely screened for HHV-6 serological markers [Sayers, 1994].

\subsection{Human herpesvirus 8 (HHV-8)}

HHV-8 is now associated with Kaposi's sarcoma in immunocompromised individuals. Though it is transmitted through organ/bone marrow transplantation, there is lack of evidence of its transfusion through blood. Serological screening of blood donors is not recommended [Engels et al., 1999].

\subsection{West Nile virus}

West Nile Virus (WNV) is a mosquito borne RNA virus of Flavivirus family. It is an important and emerging transfusion transmitted agent in North America. It was first isolated in 1937 from samples obtained in Uganda. It appeared in New York in 1999. This RNA virus can be detected by NAT. In 2002, 4200 cases of WNV were reported to centre for Disease Control and Prevention (CDC) and by 2003, number had risen to 9858. Most of WNV $(80 \%)$ cases either remain asymptomatic or have only minor flu-like symptoms. In minority of cases $(0.6 \%)$ patient can have fatal meningitis or encephalitis, especially in immune-compromised/elderly patients. In 2002, 23 cases of transfusion- and four cases of organ-transmitted WNV infection were reported and WNV-specific NAT testing was implemented as routine screening in the USA in 2003. No transfusion transmitted WNV case has been described in Europe [Bihl et al., 2007].

\subsection{Creutzfeldt-Jakob disease and variant Creutzfeldt-Jakob disease (CJD and VCJD)}

Creutzfeldt-Jakob is a form of human transmissible spongiform encephalopathy. It is characterised by mental deterioration, cerebellar dysfunction, involuntary movements and 
psychiatric disturbances. It occurs at a rate of 1 per million population annually. Transmission of CJD through blood is not established or ruled out.

Variant CJD is human form of bovine spongiform encephalopathy. It is spread through consumption of contaminated meat of infected cattle.

At present screening of blood donors for CJD as well as VCJD is not recommended.

\section{Bacterial contamination}

With improvement in screening methods for transfusion transmitted viral infections, relative risk for blood transmitted bacterial infections has increased. Approximately $57 \%$ of all Transfusion Transmitted infections and $16 \%$ of transfusion related deaths have been associated with bacterial contamination. Blood components may be contaminated with bacteria at many stages of preparation, including blood collection, processing, pooling, and transfusion. Bacteria may enter into blood components from many sources: donors' bacteremia, exposure to donor skin bacteria by venipuncture, contaminated bags and infected environment of blood banks or hospitals. The load of bacteria is determined by the storage time. Platelet units that are stored over 3 days and red cell units that are stored over 21 days are strongly associated with an increased risk of bacterial reactions.

Packed RBC's and FFP are stored at cold temperatures, so they are not common sources of bacterial contamination. Some gram negative bacterias like Yersinia, Serratia, Acinetobacter, Pseudomonas, and Escherichia species can grow at temperatures as low as $1-6^{\circ} \mathrm{C}$ and can therefore be transmitted through packed red cells [Dzieczkowski et al, 2008].

Platelet concentrates are stored at room temperature and are more likely to contain the skin contaminants including coagulase-negative staphylococci. Both staphylococcus and streptococcus infections can be transmitted through stored platelets. It is estimated that 1 in $1,000-2,000$ platelet component is contaminated with bacteria. Risk of death is 1 in 17,000 cases of sepsis associated transfusion with RDP's (random donor platelets) and 1 in 61,000 when transfused platelets by apheresis.

Recipients of blood contaminated with bacteria may develop fever with chills, followed by development of septic shock, DIC and death. Symptoms may develop within minutes of initiation of transfusion or may take several hours. The course may be abrupt, fast and fulminant. When reaction is suspected, transfusion should be immediately stopped. Broad spectrum antibiotics should be stopped. Shock should be treated. Blood bank should be notified. Blood component bag should be sent for Gram staining and culture.

\subsection{Syphilis}

Syphilis is caused by infection with Treponema pallidum. It is spread primarily through sexual contact. T. Pallidum can also be transmitted by vertical transmission from mother to fetus or through blood if donor is already infected. Its transmission through transmission has become extremely rare after implementation of the serological tests for antibodies to T. Pallidum.

\subsection{Rocky mountain spotted fever (RSMF)}

It is a severe tick borne disease caused by Rickettsia ricketsii - a bacterium. The disease is endemic in most part of the United States. RMSF is characterized by the sudden onset of 
moderate to high fever, which normally persists for 2-3 weeks, if untreated. Other typical symptoms include headache, myalgia, and petechial rash, and early RMSF may be confused with meningitis. RMSF is transmitted mainly through the bites of infected ticks. Currently, no specific questions or assays are used for screening and testing of serologic markers of $R$. rickettsii in blood donors.

\subsection{Malaria}

Malaria is an important parasitic infectious disease worldwide. Malaria is endemic in tropical and sub-tropical regions in Asia and Africa, with up to 300 million infections and one million deaths annually. It is caused by four species of Plasmodium, namely vivax, ovale, malariae and falciparum. P. Falciparum may result in severe complications and/or death. It is spread primarily by bite of the infected female Anopheles mosquito. It can also be transmitted from infected mother to her fetus or from an infected blood donor to the recipient. Patients of chronic hemolytic anemia, as of thalassemia are on regular packed $\mathrm{RBC}^{\prime} \mathrm{s}$ infusion and are at risk for malaria.

\subsection{Chagas disease}

The etiological agent is a protozoan parasite - Trypanosoma cruzi. It is endemic in Central and South America and parts of Mexico. Acute infection presents as fever, lymphadenopathy, hepatosplenomegaly, cardiomegaly and mega-esophagus. T. cruzi is transmitted from an infected vector to a person through feces deposited on the skin at the time of bite. The agent can also be transmitted vertically from mother to infant and through blood transfusion and organ transplantation.

Donors who were born or have lived in endemic areas for more than 1 year are more likely to be positive for T. cruzi antibodies. The majority of patients diagnosed with Transfusion Transmitted Chagas disease in North America have been found to be immunosuppressed.

Screening methods, such as inquiry about travel history and testing for serologic markers, are neither sensitive nor specific enough to effectively identify asymptomatic blood donors. Leukodepletion may reduce the risk of transfusion transmitted Chagas' disease [Leiby, 2000].

\section{Toxoplasmosis}

Toxoplasmosis is a zoonosis caused by Toxoplasma gondii, a parasite that is hosted in cats and dogs and has three forms - trophozoites, cysts and oocysts. About 5 million people are affected worldwide. The infection is usually asymptomatic or causes minor symptoms like fever, malaise and cutaneous rash. It can cause myocarditis and meningo-encephalitis in immunocompromised individuals; and fetal death in a pregnant female. The seroprevalence of antibodies to T. gondii increases with age and varies from $8 \%$ to $60 \%$.

It has been suggested that people who are at increased risk of toxoplasmosis, such as immunosuppressed individuals and pregnant women, receive T. gondii antibody-negative 
blood components for transfusion. The universal program of leukodepletion that is currently carried out in Canada may reduce the risk of transfusion transmitted toxoplasmosis.

\subsection{Leishmaniasis}

Leishmaniasis is caused by Leishmania donovani and affects nearly 12 million people in tropical and subtropical areas. Acute infection is often subclinical and chronic infection usually leads to anemia, lymphadenopathy and hepatosplenomegaly. Transmitted usually by infected vector - the sandfly, it can also be transmitted by blood transfusion. Due to global travel of diverse population and costly testing, leishmaniasis is now prevalent in 90 countries. Individuals returning to the US from combat zones in Iraq are currently deferred for blood donation for one year [Bihl et al., 2007].

\subsection{Babesiosis}

It is a zoonotic disease caused by Babesia microti. Babesia is a genus of protozoal piroplasm. Usually patient is asymptomatic or has mild symptoms like fever and headache. Patient may have severe anemia and hemolytic anemia. The disease is severe in infants, older patients, splenectomized and immunocompromised individuals. Usual transmission is by bite of deer ticks. There is low risk of transmission through blood. Effective screening methods for blood donors are not available.

\section{Nematodes - Microfilariasis}

Filaria is a disease seen in tropical countries like India in Asia. Microfilariae present in a donor's blood having filaria can be transmitted by blood transfusion. These may circulate in the recipient's blood but do not develop into adult worms. Mortality is not documented after such incidence but it may give rise to morbidity in transfusion recipients in terms of allergic reaction [Choudhary et al., 2003]. Transfusion associated filarial infection can increase morbidity in endemic areas. Blood donors with active history of filarial infection should be deferred from donating blood. Filarial antigen detection test may be employed as a screening test for blood donors.

\section{Prevention of transfusion transmitted infections}

1. Transfusion of non-infected blood/blood products: Etiological agent present in donor's blood can escape detection. Development of antibodies against the etiological organism takes time. So screening tests dependent on antibody detection fail to detect infection in early period. After use of NAT testing, this window period for HIV, Hepatitis B and Hepatitis C is reduced.

2. Encouraging voluntary blood donation: In developed countries, the majority of blood donors are voluntary, whereas in developing countries, majority of blood donors are replacement donors. The incidence of blood transmitted infections is much lower in the countries having majority of transfusions from voluntary donation.

3. Donor deferral: Current strategies to prevent transfusion transmitted malaria are based on risk group assessment and donor deferral for 4-12 months for visitors from low 
endemic areas to high endemic countries and 3-5 years (or permanently) for donors with a history of residence in an endemic area. However, this policy may lead to unaffordable loss of blood donation. That is why the policy of travel based risk assessment is combined with serological screening tests in some countries.

4. Immunization: Hepatitis B should be prevented by vaccination. HIV vaccine is being developed. Hepatitis C vaccine is not available at present. More vaccines should be developed to prevent transfusion of transmitted infections.

5. Prevention of infection of stored blood/blood products: Storage system in blood bank has to provide infection free environment.

6. Use of infection free equipment for transfusion: Use of disposable syringes/needles etc will decrease the risk of transmission of infections.

7. Education: HIV transmission can be prevented by increasing awareness, and first AID education of health workers. Unnecessary blood donations should be avoided to decrease the risk factor.

\section{References}

[1] Bihl F., Castelli D., Marincola F., Dodd R. Y. \& Brandes C. Transfusion transmitted infections. J Transl Med 2007; 5: 25 Available:

http://www.ncbi.nlm.gov/pmc/articles/PMC1904179/ Accessed on 06/07/2011

[2] Biswas R., Tabor E., Hsia C. C., Wright D. J., Laycock M. E., Feibig E. W., Peddada L., Smith R., Schreiber G. B., Epstein J. S., Nemo G. J. \& Busch M. P. Comparative sensitivity of HBV NAT and HBsAg assays for detection of acute HBV infection. Transfusion 2003; 43: 788-798.

[3] Blajchman M. A., Goldman M., Freedman J.J. \& Sher G. D. Proceedings of a consensus conference: prevention of post-transfusion $\mathrm{CMV}$ in the era of universal leukoreduction. Transfus Med Rev 2001; 15: 1-20.

[4] Blajchman M. A. The clinical benefits of the leukoreduction of blood products. J Trauma 2006; 60: S83-90.

[5] Canadian Blood Services (CBS). Nucleic acid testing for HIV May 2001. Available: http://www.bloodservices.Ca/cent Apps. Accessed on 26/08/2011

[6] Choudhary N., Murthy P. K., Chatterjee R. K., Khan M. A. \& Ayyagri A. Transmission of filarial infection through blood transfusion. Ind J Pathol Microbiol 2003; 46: 367370 .

[7] Dzieczkowski J. S. \& Anderson K. C. Transfusion Biology and Therapy In: McGraw Hill: Harrison's Principles of Internal Medicine 2008, pp 707-713.

[8] Engels E. A., Eastman H., Ablashi D. V., Wilks R. J., Braham J. \& Manns A. Risk of transfusion associated transmission of human herpes virus 8. J Natl Can Inst 1999; 20: $1773-1775$.

[9] Koenigbauer U. F., Eastlund T. \& Day J. W. Clinical illness due to parvovirus B19 infection after infusion of solvent/detergent-treated pooled plasma. Transfusion 2000; 40: 1203-1206. 
[10] Leiby D. A. Epidemiological aspect of transfusion transmitted babesiosis and chagas' disease. The compendium. 53 ${ }^{\text {rd }}$ AABB annual meeting. 2000; Washington DC: 209213.

[11] Moor A. C. E., Dubbelman T. M. A. R., VanSteveninck J. \& Brank A. Transfusion transmitted diseases: risks, prevention and perspectives. Eu J Haematol 1999; 62: 118.

[12] Murphy E. L., Glynn S. A., Fridey J., Smith J. W., Wright D. J., Newman B., Gibble J. W., Ameti D. I., Nass C. C., Schreiber G. B. \& Nemo G. J. Increased prevalence of infectious diseases and other adverse outcomes in human T-lymphotropic viruses types I and II- infected blood donors. Retrovirus Epidemiology Donor Study (REDS) Study Group. J Infect Dis 1997; 176: 1468-1475.

[13] Murphy E. L., Wang B., Sacher R. A., Fridey J., Smith J. W., Nass C. C., Newman B., Ownby H. E., Garratty G., Hutching S. T. \& Schreiber G. B. Respiratory and urinary tract infections, arthritis and asthma associated with HTLV-I and HTLV-II infection. Emerg Infect Dis 2004; 10: 109-116.

[14] Pathak S. \& Chandrashekhar M. (2010). Nucleic acid testing: Redefining security in blood screening. Available: http://www.maxhealthcare.in/ max-medical-journal/september2010/nuclearacid_testing.html Accessed on 20/08/2011

[15] Plentz A., Hahn J., Knoll A., Holler E., Jilg W. \& Modrow S. Exposure of hematologic patients to Parvovirus B19 as a contaminant of blood cell preparations and blood products. Transfusion 2005; 45: 1811-1815.

[16] Public Health Agency of Canada. Transfusion transmitted diseases/infections. Modified on 2003-05-12. Available: www.phac-aspc.gc.ca/hcai-iamss Accessed on $15 / 06 / 2011$

[17] Sayers M. H. Transfusion transmitted viral infections other than hepatitis and human deficiency virus infection. Cytomegalovirus, Epstein-Barr virus, human herpes virus 6 and human parvovirus B 19. Arch Pathol Lab Med 1994; 118: 346-349.

[18] Sher G. D. Leukoreduction of the blood supply. May 1999 Available: http://www.bloodservices.ca/CentreApps/Internet/UW_V502_MainEngine.nsf/r esources/Leukoreduciton/\$file/leuko_position_paper.pdf Accessed on $26 / 08 / 2011$

[19] Singh B. Nucleic acid testing (NAT) screening of blood donors in India: a project report, International Hospital Federation reference book 2008/2009, pp 66-67.

[20] Transfusion transmitted diseases. - Blood Book, Blood information for life. Available: www.bloodbook.com/trans-tran.html Accessed on 20/08/2011

[21] Vamvakas E. C. Is white blood cell reduction equivalent to antibody screening in preventing transmission of cytomegalovirus by transfusion? A review of literature and meta-analysis. Transfus Med Rev 2005; 19: 181-199.

[22] Wiedemann M., Kluwick S., Walter M., Fauchald G., Howe J., Bronold M. \& Zauke M. HIV-I, HCV and HBV window reduction by the new Roche Cobos (R) Taqscreen MPX test in (sero-converting donors). J Clin Vir 2007; 39: 282-287. 
[23] Wu C. G., Mason B., Jong J., Erdman D., McKernan L., Oakley M., Soucie M., Evatt B. \& Yu M. Y. Parvovirus B19 transmission by a high-purity factor VIII concentrate. Transfusion 2005; 45: 1003-1010. 


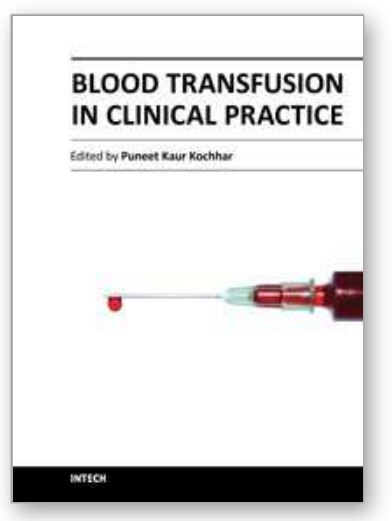

\author{
Blood Transfusion in Clinical Practice \\ Edited by Dr. Puneet Kochhar
}

ISBN 978-953-51-0343-1

Hard cover, 272 pages

Publisher InTech

Published online 16, March, 2012

Published in print edition March, 2012

Blood Transfusion in Clinical Practice focuses on the application of blood transfusion in different clinical settings. The text has been divided into five sections. The first section includes a chapter describing the basic principles of $\mathrm{ABO}$ blood group system in blood transfusion. The second section discusses the use of transfusion in various clinical settings including orthopedics, obstetrics, cardiac surgery, etc. The third section covers transfusion transmitted infections, while section four describes alternative strategies to allogenic blood transfusion. The last section speculates over immunomodulatory effects of blood transfusion.

\title{
How to reference
}

In order to correctly reference this scholarly work, feel free to copy and paste the following:

Pankaj Abrol and Harbans Lal (2012). Transfusion-Transmitted Bacterial, Viral and Protozoal Infections, Blood Transfusion in Clinical Practice, Dr. Puneet Kochhar (Ed.), ISBN: 978-953-51-0343-1, InTech, Available from: http://www.intechopen.com/books/blood-transfusion-in-clinical-practice/transfusion-transmitted-bacterial-viraland-protozoal-infections

\section{INTECH}

open science | open minds

\section{InTech Europe}

University Campus STeP Ri

Slavka Krautzeka 83/A

51000 Rijeka, Croatia

Phone: +385 (51) 770447

Fax: +385 (51) 686166

www.intechopen.com

\section{InTech China}

Unit 405, Office Block, Hotel Equatorial Shanghai

No.65, Yan An Road (West), Shanghai, 200040, China

中国上海市延安西路65号上海国际贵都大饭店办公楼405单元

Phone: +86-21-62489820

Fax: +86-21-62489821 
(C) 2012 The Author(s). Licensee IntechOpen. This is an open access article distributed under the terms of the Creative Commons Attribution 3.0 License, which permits unrestricted use, distribution, and reproduction in any medium, provided the original work is properly cited. 